\title{
PENGARUH STRUKTUR BIROKRASI TERHADAP IMPLEMENTASI KEBIJAKAN PROGRAM PELAYANAN KESEHATAN PEDULI REMAJA (PKPR) (Studi di Puskesmas Kabupaten Gunungkidul)
}

\author{
THE INFLUENCE OF BUREAUCRATICSTRUCTURE TOWARD POLICY \\ IMPLEMENTATION OF HEALTH SERVICES AND CARE FOR \\ ADOLESCENT(PKPR)PROGRAM \\ (Study at the Health Centers In Gunungkidul)
}

Fani Mega Maulidia

Fakultas Kesehatan Masyarakat, Universitas

Airlangga, Surabaya

Email: maulidia.fani@gmail.com

\begin{abstract}
Adolescence phase refers to a period by which physical, psycology, and intellectual grow and develop rapidly. In adolescence phase, oneself tends to have a great curiosity, once when they take inappropriate decision, they will be trapped in a risky state. One of the solutions to overcome juvenile problem is by conductingHealth Services and Care for Adolescent (Indonesian: Pelayanan Kesehatan Peduli Remaja or PKPR). PKPR is health service and care provided for adolescents.

This study was classified as quantitative analytic methods. According to the time of the study needed, this study was classified as a cross-sectional study; a study that conducted simultaneously at one particular time. This study used primary data with health centers as unit of analysis, consisting of 24 health centers in Gunung Kidul Regency. The results showed that the variables of SOP and fragmentation significantly influenced implementation of policies concerning to PKPR.

The officer of PKPR is expected to maintain cooperation with another program officer as the cross-program is very influential for the success of PKPR program.

Keywords: bureaucratic structure, Health Services and Care for Adolescent(PKPR), reproductive health.
\end{abstract}




\begin{abstract}
ABSTRAK
Masa remaja merupakan periode dimana fisik, psikologi, dan intelektual tumbuh dan berkembang dengan cepat. Pada masa remaja cenderung memiliki rasa ingin tahu yang sangat besar, ketika mereka mengambil keputusan yang salah, mereka akan terjebak dalam keadaan beresiko. Salah satu solusi untuk mengatasi masalah remaja adalah melalui Pelayanan Kesehatan Peduli Remaja atau PKPR. PKPR adalah pelayanan kesehatan yang diberikan untuk remaja.

Penelitian ini dilakukan dengan metode analitik kuantitatif. Sesuai dengan waktu penelitian yang dilakukan, penelitian ini diklasifikasikan sebagai studi cross-sectional; sebuah studi yang dilakukan bersamaan pada satu waktu tertentu. Penelitian menggunakan data primer dengan Puskesmas sebagai unit analisis, yang terdiri dari 24 Puskesmas di Kabupaten Gunung Kidul. Hasil penelitian menunjukkan bahwa variabel SOP dan fragmentasi secara signifikan mempengaruhi implementasi kebijakan program PKPR.

Saran yang dapat diberikan yaitu petugas PKPR di Puskesmas diharapkan agar bekerjasama dengan petugas program lain sebagai lintas program karena sangat berpengaruh bagi keberhasilan program PKPR.

Kata kunci: struktur birokrasi, Pelayanan Kesehatan Peduli Remaja (PKPR), kesehatan reproduksi.
\end{abstract}

\section{PENDAHULUAN}

Jumlah penduduk di Indonesia, seperempat diantaranya adalah remaja. Masa remaja adalah masa transisi dari masa kanak-kanak menuju dewasa, oleh karena itu remaja mempunyai tanggung jawab dalam perkembangannya. Remaja harus mendapatkan identitas diri yang positif agar dapat berkembang sebagai dewasa muda yang sehat dan produktif (Depkes, 2003).

Menurut World Health Organization (WHO) yang termasuk kedalam kelompok remaja yaitu mereka yang berusia 10-19 tahun. Secara demografis kelompok remaja dibagi menjadi kelompok usia 10-14 tahun dan kelompok usia 15-19 tahun. UndangUndang No.23 tahun 2002 tentang Perlindungan Anak menyebutkan setiap orang yang berusia sampai dengan 18 tahun sebagai "anak", sehingga berdasarkan Undang-Undang tersebut sebagian besar remaja termasuk dalam kelompok anak. Proporsi penduduk remaja berusia 10-19 tahun pada tahun 2010 sekitar $18,3 \%$ dari total penduduk atau sekitar 43 juta jiwa berdasarkan data Proyeksi Penduduk Indonesia (Kemenkes RI, 2014).

Periode terjadinya pertumbuhan dan perkembangan pesat baik fisik, psikologis maupun intelektual disebuat dengan masa remaja. Pada masa remaja cenderung memiliki rasa keingintahuan yang besar, menyukai tantangan dan petualangan serta berani menanggung resiko atas apa yang mereka perbuat tanpa pertimbangan yang matang. Jika keputusan yang diambil remaja tidak tepat maka mereka akan jatuh ke dalam perilaku beresiko dan kemudian harus menanggung akibat atas perbuatannya (Depkes RI, 2007).

Menurut (Conrad, 2000), data mengenai perilaku hubungan seks pranikah pada pelajar terutama di kota besar beberapa tahun terakhir cukup signifikan. Survei yang dilakukan Yayasan Pelita Ilmu di plaza dan mall Jakarta menunjukkan bahwa $42 \%$ dari 117 remaja 13-20 tahun pernah berhubungan seks dan lebih dari 50\% diantaranya masih aktif berhubungan seks dalam 1-3 bulan terakhir. Menurut Utomo, dkk (1998) bahwa sebuah survey terhadap pelajar SMA di Manado menemukan 20\% pada remaja lakilaki melakukan seks pranikah dan $6 \%$ pada remaja perempuan (Kemenkes RI, 2014).

Hasil SDKI 2012 menunjukkan bahwa 7\% remaja perempuan $15-19$ tahun pernah melahirkan. Hal tersebut sangat memprihatinkan karena kehamilan dan persalinan pada remaja dibawah umur 19 tahun dapat meningkatkan resiko kematian ibu dan bayi (Kemenkes RI, 2014).

Pada tahun 2015 di Provinsi Daerah Istimewa Yogyakarta jumlah angka persalinan remaja mencapai 1039. 
Kabupaten/kota yang terdapat di Provinsi Daerah Istimewa Yogyakarta meliputi Kota sebesar 90 kasus, Bantul sebesar 329 kasus, Kulonprogo sebesar 106 kasus, Gunungkidul sebesar 404 kasus, dan Sleman sebesar 110 kasus (Dinkes Provinsi DIY, 2016).

Angka persalinan remaja usia 15-19 tahun di Kabupaten Gunungkidul dari tahun ke tahun merupakan kasus tertinggi dibandingkan dengan kabupaten/kota yang lain yaitu pada tahun 2013 sebesar 628 kasus, kemudian menurun pada tahun 2014 yaitu sebesar 366 kasus, dan kemudian mengalami peningkatan pada tahun 2015 yaitu sebesar 404 kasus (Dinkes Kabupaten Gunungkidul, 2016).

Salah satu upaya yang dapat dilakukan agar permasalahan remaja dapat diatasi yaitu dengan diselenggarakannya Pelayanan Kesehatan Peduli Remaja (PKPR). PKPR merupakan pelayanan kesehatan yang ditujukan dan dapat dijangkau oleh remaja, menyenangkan, menerima remaja dengan tangan terbuka, menghargai remaja, menjaga kerahasiaan, peka akan kebutuhan terkait dengan kesehatannya, serta efektif dan efisien dalam memenuhi kebutuhan pada remaja. PKPR dengan pengertian lain yaitu pelayanan kesehatan kepada remaja yang mengakses semua golongan remaja (Depkes RI, 2007).

Tujuan penelitian yaitu mengidentifikasi faktor struktur birokrasi meliputi SOP (Standard Operating Procedures)dan fragmentasi serta menganalisis pengaruh faktor SOP dan fragmentasi terhadap implementasi kebijakan program PKPR.

\section{METODE PENELITIAN}

Jenis penelitian yang digunakan adalah analitik dengan pendekatan metode kuantitatif.

Ditinjau dari waktu pelaksanaan penelitian,penelitian ini termasuk penelitian Cross Sectional karena dilaksanakan sekaligus pada satu waktu tertentu.

Populasi dalam penelitian ini yaitu seluruh Puskesmas di Kabupaten Gunungkidul dengan jumlah 30 Puskesmas. Perhitungan besar sampeldengan menggunakan teknik Simple Random Samplingdengan derajat penyimpangan $5 \%$. Berikut ini perhitungan besar sampel penelitian.Jumlah Puskesmas di Kabupaten Gunungkidul $\mathrm{N}=30$ Puskesmas $; \mathrm{p}=0,5$ maka :

$\mathrm{n}=\frac{Z^{2} 1-\alpha / 2 P(1-P) N}{d^{2}(N-1)+Z^{2} 1^{\alpha} / 2 P(1-P)}$

Keterangan:

$1-\alpha=95$ (nilai table $\mathrm{Z}$ dengan nilai signifikansi 5\%)

$\mathrm{P}=$ estimasi proporsi 0,$5 ; \mathrm{q}=1-\mathrm{p}$

$\mathrm{d}=$ Tingkat kepercayaan/ketepatan (

$0,1)$

$\alpha \quad=0,2$

$\mathrm{N} \quad=$ Populasi (30)

$\mathrm{n} \quad=$ Besar sampel

$\mathrm{n}=\frac{(1,96)^{2} \cdot 0,5(1-0,5) 30}{(0,1)^{2}(30-1)+(1,96)^{2}(0,5)(1-0,5)}$

$\mathrm{n}=\frac{3,84.0,5(0,5) 30}{0,01(29)+(3,84)(0,5)(0,5)}$

$\mathrm{n}=\frac{28,8}{0,29+0,96}$

$\mathrm{n}=\frac{28,8}{1,25}$

$\mathrm{n}=23,04$

$\mathrm{n}=24$ Puskesmas

Berdasarkan perhitungan besar sampel, didapatkan 24 Puskesmas yang akan menjadi sampel penelitian yang dipilih secara acak oleh peneliti.

Penelitian dilakukandengan wawancaralangsung kepada 24 Kepala Puskesmas dan 24 petugas program PKPR di Kabupaten Gunungkidul. Regresi Logistik Ordinal digunakan dalam pengolahan data dan analisis data pada penelitian ini. Penelitian dilakukan pada bulan Maret-April Tahun 2016 di Kabupaten Gunungkidul.

\section{HASIL PENELITIAN DAN PEMBAHASAN}

\section{Hasil Implementasi Kebijakan Program PKPR di Puskesmas Kabupaten Gunungkidul}

Berikut ini akan dijabarkan tentang hasil penelitian mengenai implementasi dan struktur birokrasi. 
Tabel 1 menunjukkan distribusi frekuensi kategori implementasi. Kegiatan yang dilakukan Puskesmas pada pelaksanaan program PKPRdisebut dengan implementasi program PKPR. Sebesar 50,0\% Puskesmas memiliki implementasi program PKPR kurang.

Tabel 2 menunjukkan distribusi frekuensi kategori SOP. SOP pada implementasi program PKPR merupakan mekanisme pelaksanaan kegiatan dalam program PKPR. Sebesar 54,2\% mempunyai SOP kurang jelas.

Tabel 3 menunjukkan distribusi frekuensi kategori fragmentasi. Fragmentasi pada implementasi program PKPR merupakan penyebaran tanggung jawab pada satu lingkup kebijakan diantara beberapa unit organisasi. Sebesar 54,2\% mempunyai sedikit fragmentasi pada implementasi program PKPR.

\section{Hasil Analisis Pengaruh Struktur Birokrasi terhadap Implementasi Kebijakan Program PKPR}

SOP

Dari tabel 4 diperoleh hasil antara SOP dengan implementasi bahwa ada kecenderungan semakin kurang jelas SOP maka semakin kurang implementasi. Hasil uji Regresi Logistik Ordinal diketahui bahwa SOP berpengaruh secara signifikan terhadap implementasi program PKPR, yaitu dengan nilai $p(0,000)<\alpha(0,05)$. Hal ini berarti jika SOP jelas pada pelaksanaan program PKPR maka kemungkinan implementasi program PKPR dapat terlaksana dengan baik.

\section{Fragmentasi}

Dari tabel 4 diperoleh hasil antara fragmentasi dengan implementasi bahwa terdapat kecenderungan pola nilai yang teratur dimana semakin banyak fragmentasi maka implementasi semakin kurang. Hasil uji Regresi Logistik Ordinal diketahui bahwa fragmentasi berpengaruh secara signifikan terhadap implementasi, yaitu dengan nilai $\mathrm{p}(0,007)<\alpha(0,05)$. Hal ini berarti jika fragmentasi sedikit pada pelaksanaan program PKPR maka kemungkinan implementasi program PKPR dapat terlaksana dengan baik dibandingkan adanya fragmentasi yang banyak.

Pada variabel fragmentasi dikategorikan menjadi tidak ada fragmentasi, sekit fragmentasi, dan banyak fragmentasi tetapi karena tidak ada fragmentasi nilainya 0 maka tidak dimunculkan dalam tabel.

\section{PEMBAHASAN}

\section{Implementasi Kebijakan Program Pelayanan Kesehatan Peduli Remaja (PKPR)}

Menurut Suharto (2011) bahwa sebuah instrument pemerintah, bukan saja dalam arti government yang hanya menyangkut aparatur negara, tetapi governance yang menyentuhpengelolaan sumber daya publik disebut dengan kebijakan (policy) .

Tabel 1 Distribusi Frekuensi Kategori Implementasi pada Program PKPR di Puskesmas Kabupaten Gunungkidul Tahun 2016.

\begin{tabular}{lrr}
\hline \multicolumn{1}{c}{ Kategori Implementasi } & Frekuensi & \multicolumn{1}{c}{ Persen (\%) } \\
\hline Implementasi baik & 10 & 41,7 \\
\hline Implementasi kurang & 12 & 50,0 \\
\hline Implementasi buruk & 2 & 8,3 \\
\hline Total & 24 & 100,0 \\
\hline
\end{tabular}

Tabel 2Distribusi Frekuensi Kategori SOP pada Program PKPR di Puskesmas Kabupaten Gunungkidul Tahun 2016.

\begin{tabular}{lrr}
\multicolumn{1}{c}{ Kategori Implementasi } & Frekuensi & \multicolumn{1}{c}{ Persen (\%) } \\
\hline Implementasi baik & 10 & 41,7 \\
\hline Implementasi kurang & 12 & 50,0 \\
\hline Implementasi buruk & 2 & 8,3 \\
\hline Total & 24 & 100,0 \\
\hline
\end{tabular}

Tabel 3Distribusi Frekuensi Kategori Fragmentasi pada Program PKPR di Puskesmas Kabupaten Gunungkidul Tahun 2016. 


\begin{tabular}{lrr}
\multicolumn{1}{c}{ Kategori Implementasi } & Frekuensi & \multicolumn{1}{c}{ Persen (\%) } \\
\hline Implementasi baik & 10 & 41,7 \\
\hline Implementasi kurang & 12 & 50,0 \\
\hline Implementasi buruk & 2 & 8,3 \\
\hline Total & 24 & 100,0 \\
\hline
\end{tabular}

Tabel 4 Hasil Tabulasi Silang Pengaruh SOP dan Fragmentasi terhadap Implementasi Kebijakan Pelayanan Kesehatan Peduli Remaja (PKPR) di Puskesmas Kabupaten Gunungkidul Tahun 2016.

\begin{tabular}{|c|c|c|c|c|c|c|c|c|c|}
\hline \multirow{3}{*}{\multicolumn{2}{|c|}{ Variabel }} & \multicolumn{6}{|c|}{ Implementasi } & \multirow{2}{*}{\multicolumn{2}{|c|}{ Total }} \\
\hline & & \multicolumn{2}{|c|}{ Baik } & \multicolumn{2}{|c|}{ Kurang } & \multicolumn{2}{|c|}{ Buruk } & & \\
\hline & & $\mathrm{N}$ & $\%$ & $\mathrm{~N}$ & $\%$ & $\mathrm{~N}$ & $\%$ & $\mathrm{~N}$ & $\%$ \\
\hline \multirow[t]{3}{*}{ SOP } & Jelas & 6 & 85,7 & 1 & 14,3 & 0 & 0,0 & 7 & 100,0 \\
\hline & Kurang jelas & 4 & 30,8 & 9 & 69,2 & 0 & 0,0 & 13 & 100,0 \\
\hline & Tidak jelas & 0 & 0,0 & 2 & 50,0 & 2 & 50,0 & 4 & 100,0 \\
\hline \multirow[t]{2}{*}{ Fragmentasi } & Sedikit & 10 & 76,9 & 1 & 7,7 & 2 & 15,4 & 13 & 100,0 \\
\hline & Banyak & 0 & 0,0 & 11 & $\begin{array}{r}100 \\
0\end{array}$ & 0 & 0,0 & 11 & 100,0 \\
\hline
\end{tabular}

Kebijakan pada intinya merupakan suatu keputusan atau pilihan tindakan yang secara langsung mengatur pengelolaan dan pendistribusian sumber daya alam, finansial, dan manusia demi kepentingan publik, yaitu meliputi rakyat banyak, penduduk, masyarakat, atau warga negara. Kebijakan merupakan hasil adanya sinergi, kompromi, atau bahkan kompetisi antara berbagai gagasan, teori, ideologi, dan kepentingan yang mewakili sistem politik suatu negara.

Menurut Eystone dalam Wahab (2014) bahwa "Antar hubungan yang berlangsung diantara unit atau satuan pemerintahan dengan lingkungannya" merupakan kebijakan publik.

$$
\text { Menurut Islamy }
$$

menyimpulkan kebijakan publik (public policy) yaitu tindakan yang diterapkan dan dilaksanakan atau tidak dilaksanakan oleh pemerintah yang mempunyai tujuan atau berorientasi pada tujuan tertentu demi kepentingan seluruh masyarakat. Pada hakikatnya kebijakan publik mendasarkan pada paham bahwa kebijakan publik harus mengabdi kepada kepentingan masyarakat.

Mazmanian dan Sabatier dalam Agustino (2008) mendefinisikan implementasi kebijakan sebagai pelaksanaan keputusan kebijaksanaan dasar, biasanya dalam bentuk undang-undang tetapi dapat juga berbentuk berbagai perintah atau keputusan eksekutif yang penting atau keputusan badan peradilan.

Implementasi sering dianggap sebagai bentuk pengoperasionalisasian atau penyelenggaraan aktivitas yang telah ditetapkan berdasarkan undang-undang dan menjadi kesepakatan bersama diantara beragam pemangku kepentingan (stakeholders), aktor, organisasi, (publik atau privat), prosedur, dan teknik secara sinergistis yang digerakkan untuk bekerjasama yang bertujuan untuk menerapkan kebijakan kearah tertentu yang dikehendaki (Wahab, 2014).

Edward III (1948) mengemukakan ada empat faktor yang berpengaruh terhadap keberhasilan atau kegagalan implementasi kebijakan. Empat faktor tersebut antara lain meliputi faktor komunikasi, sumber daya (staf, informasi, wewenang, dan fasilitas), disposisi, dan struktur birokrasi (SOP dan fragmentasi..

Berdasarkan hasil penelitian menunjukkan kategori implementasi di Puskesmas Kabupaten Gunungkidul pada program PKPR bahwa sebanyak 50,0\% Puskesmas memiliki implementasi program PKPR kurang. Sebesar 62,5\% mengatakan Puskesmas tidak pernah mengikutsertakan remaja dalam merencanakan program kesehatan remaja pada kurun waktu setahun terakhir. Pada implementasi program PKPR, remaja merupakan sasaran dalam 
pelaksanaan program. Remaja meruapakan asset masa depan oleh karena itu akan lebih tepat jika remaja dilibatkan pada pelaksanaan program remaja. Remaja perlu dilibatkan secara aktif dalam perencanaan, pelaksanaan, dan penilaian pelayanan karena ide dan tindakan nyata mereka akan lebih mengenal dalam perencanaan dan pelaksanaan pelayanan karena mereka lebih mengerti kebutuhan mereka dan juga mengerti bagaimana mempengaruhi dan memotivasi teman mereka (Depkes RI, 2007).

\section{Pengaruh Struktur Birokrasi terhadap Implementasi Kebijakan Program Pelayanan Kesehatan Peduli Remaja(PKPR)}

Edward III mengidentifikasikan struktur birokrasi yaitu:

"Policy implementors may know what to do and have sufficient desire and resources to do it, but they may still be hampered in implementation by the structures of the organizations in which they serve. Two prominent characteristics of bureaucracies are standard operating prosedures (SOPs) and fragmentation. The former develop as internal respons to the limited time and resources of implementors and the desire for uniformity in the operation of complex and widely dispersed organizations; they often remain in force due to bureaucratic inertia" (Edward III, 1980).

Pelaksana kebijakan mungkin tahu apa yang harus dilakukan dan memiliki keinginan yang cukup dan sumber daya untuk melakukannya, tetapi mereka mungkin masih terhambat dalam pelaksanaannya oleh struktur organisasi yang mereka gunakan. Dua karakteristik yang menonjol dari birokrasi adalah prosedur standar operasi (SOP) dan fragmentasi. Struktur birokrasi ini dikembangkan sebagai respon internal akan waktu dan pelaksana sumber daya yang terbatas dan dimaksudkan untuk membakukan pekerjaan pada organisasi yang kompleks dan luas; struktur organisasi ini seringkali tetap berlaku dikarenakan adanya kekakuan birokrasi.

Walaupun sumber untuk mengimplementasikan suatu kebijakan dikatakan cukup dan para pelaksana (implementors) mengetahuai bagaimana melakukannya, serta mereka mempunyai keinginan untuk melakukannya tetapi implementasi kebijakan dapat tidak berjalan efektif karena struktur birokrasi yang tidak efektif.

\section{SOP (Standard Operating Procedures)}

Edward III (1980) mengemukakan pengertian SOP yaitu berbagai rutinitas yang memungkinkan pihak otoritas membuat berbagai keputusan harian.

Menurut Winarno (2014) bahwa keberadaan SOP diharapkan agar para pelaksana kebijakan dapat memanfaatkan waktu yang tersedia, menyeragamkan tindakan dari para pejabat dalam organisasiorganisasi yang kompleks dan tersebar luas sehingga akan menimbulkan fleksibilitas yang besar serta agar terjadinya suatu kesamaan dalam penerapan peraturanperaturan.

Berdasarkan pada hasil penelitian yang dilakukan di Puskesmas wilayah Gunungkidul dapat diketahui bahwa sebagian besar Puskesmas yaitu sebanyak 13 Puskesmas $(54,2 \%)$ mempunyai SOP kurang jelas pada implementasi program PKPR. Puskesmas mempunyai SOP kurang jelas yaitu sebesar 79,2\% terdapat SOP rujukan medik saja di Puskesmas dan 50,0\% mengatakan terdapat SOP tentang rujukan tetapi belum dilaksanakan. Berdasarkan Panduan Standar Nasional PKPR (2014) bahwa rujukan yang terdapat dalam program PKPR yaitu rujukan medik, rujukan sosial, dan rujukan hukum.

Menurut Depkes RI (2007) bahwa rujukan sosial mempunyai peran antara lain penyaluran pelatihan keterampilan remaja pasca rehabilitasi NAPZA serta mempersiapkan remaja pra nikah. Rujukan medis antara lain mempunyai peran dalam kelanjutan bantuan medis bagi remaja yang memerlukannya. Rujukan hukum mempunyai peran dalam kasus tindak kekerasan. 
Berdasarkan hasil uji Regresi Logistik Ordinal diketahui bahwa SOP berpengaruh secara signifikan terhadap implementasi program PKPR, yaitu dengan nilai $\mathrm{p}(0,000)$ $<\alpha(0,05)$. Hal ini berarti jika SOP jelas pada pelaksanaan program PKPR maka kemungkinan implementasi program PKPR dapat terlaksana dengan baik.

Menurut Widodo (2013) menjelaskan jika SOP tidak jelas, baik itu menyangkut mekanisme, sistem dan prosedur pelaksanaan kebijakan, pembagian tugas pokok, fungsi, kewenangan, dan tanggung jawab diantara para pelaku serta tidak harmonisnya hubungan diantara organisasi pelaksana maka akan dapat menimbulkan kegagalan pelaksanaan kebijakan.

JIka SOP jelas, maka akan semakin mudah dalam menentukan kebutuhan sumber daya. Selaian itu, semakin jelas SOP pelaksanaan kebijakan, maka akan semakin memudahkan para pelaku kebijakan untuk mengetahui, memahami, dan mendalami substansi kebijakan baik itu menyangkut tujuan, arah, kelompok sasaran, dan hasil apa yang dapat dicapai maupun dinikmati baik oleh para pelaku kebijakan maupun organisasi pelaku kebijakan. Keadaan ini akan memudahkan seseorang dalam menentukan sikap diri dan organisasinya dalam melaksanakan kebijakan (Widodo, 2013).

\section{Fragmentasi}

Menurut Edward III (1980) bahwa penyebaran tanggung jawab pada satu lingkup kebijakan diantara beberapa unit organisasi disebut dengan fragmentasi.

Dimensi fragmentasi menurut Widodo (2013) menegaskan bahwa struktur birokrasi yang terfragmentasi dapat meningkatkan gagalnya komunikasi karena akan membatasi kemampuan para pejabat tinggi untuk mengkoordinasikan semua sumber daya yang relevan dan akibat lebih lanjut dapat menimbulkan terjadinya ketidakefisienan serta pemborosan sumber daya yang langka.

Dimensi fragmentasi menegaskan jika struktur birokrasi terfragmentasi maka dapat meningkatkan kegagalan komunikasi, dimana instruksi yang dijalankan oleh para pelaksana akan terdistorsi. Fragmentasi dapat membatasi kemampuan para pejabat tinggi untuk mengkoordinasikan semua sumber dya yang relevan dalam suatu yurisdiksi tertentu, sehingga mengakibatkan terjadinya ketidakefisienan serta pemborosan sumber daya yang langka (Widodo, 2013).

Organisasi pelaksana yang terfragmentasi (terpecah atau tersebar) dapat menyebabkan distorsi dalam pelaksanaan kebijakan. Organisasi pelaksana yang semakin terfragmentasi akan semakin membutuhkan koordinasi yang intensif, sehingga menimbulkan peluang terjadinya distorsi komunikasi yang dapat menyebabkan kegagalan dalam pelaksanaan kebijakan (Widodo, 2013).

Berdasarkan pada hasil penelitian yang dilakukan di Puskesmas Kabupaten Gunungkidul dapat diketahui bahwa sebagian besar Puskesmas yaitu sebanyak 13 Puskesmas $(54,2 \%)$ mempunyai sedikit fragmentasi pada implementasi program PKPR. Sebanyak 75,0\% Puskesmas mengatakan bahwa kerja sama petugas program PKPR dengan petugas program lain sudah baik, namun ada 45,8\% mengatakan program lain tidak pernah melibatkan kegiatan program PKPR secara bersamaan.

Edward III (1980) mengemukakan bahwa tidak hanya satu lembaga yang bertanggung jawab terhadap suatu kebijakan namun ada beberapa lembaga yang ikut bertanggung jawab. Keterlibatan program lain di Puskesmas sangatlah penting karena dapat menunjang keberhasilan program PKPR. Manfaat yang bisa didapat jika kegiatan dilaksanakan bersama antara lain selain mempunyai sasaran yang sama juga dapat menghemat waktu.

Berdasarkan pada hasil uji Regresi Logistik Ordinal diketahui bahwa fragmentasi berpengaruh secara signifikan terhadap implementasi, yaitu dengan nilai $\mathrm{p}$ $(0,007)<\alpha(0,05)$. Hal ini berarti jika fragmentasi sedikit pada pelaksanaan program PKPR maka kemungkinan implementasi program PKPR dapat terlaksana dengan baik dibandingkan dengan adanya fragmentasi yang banyak.

Kerjasama yang baik dari banyak orang dapat mendorong keberhasilan 
implementasi kebijakan, oleh sebab itu, fragmentasi dapat merintangi koordinasi yang diperlukan untuk mengimplementasikan suatu kebijakan serta dapat memicu pemborosan sumber daya yang terbatas (Widodo, 2013).

Penelitian serupa juga dilakukan oleh Arsani (2013) dengan judul "Peranan Program Pelayanan Kesehatan Peduli Remaja (PKPR) terhadap Kesehatan Reproduksi Remaja di Kecamatan Buleleng”. Hasil penelitian antara lain mengatakan bahwa tidak hanya pemegang program saja yang menjalankan program PKPR, tetapi tentunya memerlukan kerja sama dengan staf ataupun bagian lain. Program UKS (Usaha Kesehatan Sekolah), program PKM (Pendidikan Kesehatan Masyarakat), program kesehatan gigi, program KIA/KB (Kesehatan ibu dan anak/Keluarga berencana), pelayanan poliklinik khususnya pelayanan IMS (infeksi menular seksual) dan HIV/AIDS, pelayanan laboratorium dan P2M (Pencegahan penyakit menular) merupakan staf atau bagian lain yang diikutkan pada pelaksanaan program PKPR. Diharapkan dengan adanya kerja sama lintas bagian ini, maka dapat menunjang keterlaksanaan dan kelancaran kegiatan program PKPR.

\section{SIMPULAN DAN SARAN}

Berdasarkan hasil analisa data dan pembahasan pada penelitian ini, maka dapat disimpulkan bahwa faktor struktur birokrasi yang terdiri dari variabel SOP di Puskesmas Kabupaten Gunungkidul menunjukkan sebanyak 54,2\% Puskesmas mempunyai SOP kurang jelas karena terdapat SOP rujukan medik saja di Puskesmas dan terdapat SOP tentang rujukan tetapi belum dilaksanakan. Variabel fragmentasi menunjukkan sebanyak 54,2\% Puskesmas mempunyai sedikit fragmentasi pada implementasi program PKPR.Hal tersebut didukung oleh kerja sama petugas program PKPR dengan petugas program lain sudah baik, namun program lain tidak pernah melibatkan kegiatan program PKPR secara bersamaan.Variabel implementasi program PKPR menunjukkan sebanyak 50,0\% Puskesmas memiliki implementasi program
PKPR kurang sebab Puskesmas tidak pernah mengikutsertakan remaja dalam merencanakan program kesehatan remaja pada kurun waktu setahun terakhir

Variabel SOP menunjukkan jika SOP jelas maka kemungkinan implementasi program PKPR dapat terlaksana dengan baik $(p=0,000), \quad$ dan variabel fragmentasi menunjukkan jika fragmentasi sedikit maka kemungkinan implementasi program PKPR dapat terlaksana dengan baik dibandingkan dengan adanya fragmentasi yang banyak $(\mathrm{p}=0,007)$.

\section{SARAN}

Kepada Puskesmas agar Agar menggunakan SOP yang sudah ada mengenai program remaja sehingga pelaksanaan pelayanan dapat berjalan optimal dan supaya membuat SOP rujukan hukum serta sosial selain rujukan medik seperti yang terdapat pada Pedoman Standar Nasional PKPR.

Agar meningkatkan hubungan kerja sama dengan petugas program lain karena peran lintas program sangatlah penting apalagi masalah remaja sangat beragam sehingga sangat dibutuhkan keterlibatan program lain yang mempunyai tujuan yang sama. Selain itu juga memperluas kemitraan selain lintas program juga peran lintas sektor tingkat kabupaten dan tingkat kecamatan sangatlah mendukung keberhasilan program PKPR.

\section{DAFTAR PUSTAKA}

Agustino, L. (2006). Politik dan Kebijakan Publik. Bandung: AIPI Bandung.

Arsani. (2013). Peranan Program PKPR terhadap Kesehatan Reproduksi Remaja di Kecamatan Buleleng. Jurnal Ilmu Sosial dan Humaniora, 2(1), 136.

Depkes RI. (2003). MATERI PELAYANAN KESEHATAN PEDULI REMAJA (PKPR). Jakarta: Departemen Kesehatan RI.

Depkes RI. (2007). Modul Pelatihan Pelayanan Kesehatan Peduli Remaja (PKPR). Jakarta: Departemen Kesehatan RI. 
Dinkes Kabupaten Gunungkidul. (2014).

Laporan Persalinan Remaja Tahun 20132015.

Dinkes Provinsi DIY. (2016) Laporan

Persalinan Remaja Tahun 2013-2015.

Edwards III, G. C. (1980). Implementing Public Policy. Washington: Congressional Quarterly Press.

Islamy, I. (1997). Prinsip-Prinsip Perumusan Kebijakan Negara. Jakarta: Bumi Aksara.

Kemenkes RI. (2014).Pedoman Standar Nasional Pelayanan Kesehatan Peduli Remaja (PKPR). Jakarta: Kementerian Kesehatan RI.

Suharto, E., (2011). Kebijakan Sosial sebagai Kebijakan Publik. Bandung: Alfabeta.

Wahab, A., Solichin. (2014). Analisa Kebijakan dari Formulasi ke Implementasi Kebijakan Negara. Cetakan Kedua. Jakarta: Bumi Aksara.

Widodo, J. (2013). Analisis Kebijakan Publik: Konsep dan Aplikasi Analisis

Proses Kebijakan Publik. Malang: Bayu Media.

Winarno, B. (2014). Kebijakan Publik (Teori, Proses dan Studi Kasus). Yogyakarta: CAPS 
JURNAL ILMIAH KESEHATAN MEDIAHUSADA ｜ＶOLUME 06/NOMOR 02/OKTOBER 2017 